\title{
Parallel-mounted On-premise Letter Height and Sign Size
}

\section{Philip M. Garvey*}

Principal

Garvey \& Associates

pgarveyandassociates.com

\section{Jennifer Klena}

Associate

Garvey \& Associates

jklena72@outlook.com

${ }^{*}$ corresponding author

\section{BACKGROUND AND OBJECTIVES}

Research conducted by Zineddin et al. (2005) proved what sign manufactures and owners had previously merely assumed, that on-premise signs mounted perpendicular to oncoming motorists (e.g., projecting signs) are more detectable and readable from a greater distance and smaller size than their parallel-mounted (e.g., wall signs) counterparts. Garvey (2006) conducted a subsequent analysis to determine the difference between the two, namely the text size required for sign legibility and driver safety. The study resulted in a mathematical model and accompanying look-up table that could provide guidance on determining minimum parallel-mounted on-premise commercial sign letter heights.

While necessary and useful, that study did not include a field verification stage, so the recommendations and equations could result in some anomalies when applied to signs in the real-world. Also, while the study recommended specific minimum letter heights for parallel signs, it did not address an overall minimum sign size that could comfortably accommodate those letter heights.

The objective of the current study is two-fold, first to conduct a small-scale field validation to determine if the minimum letter heights predicted by Garvey (2006) provide sufficient legibility, or if some modifications are required. Second, sign size will be addressed by developing a look-up table or calculation that would provide minimum parallel sign square footage required for the recommended parallel sign letter heights.

\section{Abstract /}

Research and common sense attest to the fact that on-premise projecting signs are more detectable and are readable further away and at smaller sizes than wall-mounted signs. The objective of the current study was to conduct a small-scale field validation of earlier research on minimum letter heights for wall signs and to provide associated minimum square footage for these signs. Eight wall signs that varied in letter height and lateral offset were identified for evaluation on two roadways that varied in posted speed limit and cross-section in Nags Head, North Carolina. Using an empirical procedure involving driving and walking toward the signs, the legibility distances for these signs were evaluated and were found to compare favorably to past research that employed an analytical approach. An equation to determine sign size in square feet was also developed. Future research to further these findings is outlined.

Keywords /

on-premise signs; wall signs; commercial signs; visibility; legibility. 


\section{PROCEDURE}

\section{Field Validation}

\section{Roadway Descriptions and Sign Locations}

A set of eight parallel-mounted on-premise signs were identified in Nags Head, North Carolina (see Appendix A). The signs varied in letter height and lateral offset from the roadway. The roadways varied in posted speed limit and crosssection (e.g., number and width of lanes). The two roadways are:

1. North Carolina Highway 12 (NC 12 / South Virginia Dare Trail) is a two-way, two-lane primary highway with a posted speed limit of $35 \mathrm{mph}$. 10 -foot wide travel lanes are separated by a solid double yellow no passing centerline. NC 12 has solid white edge lines and 3.5-foot wide shoulders (see Figure 1).

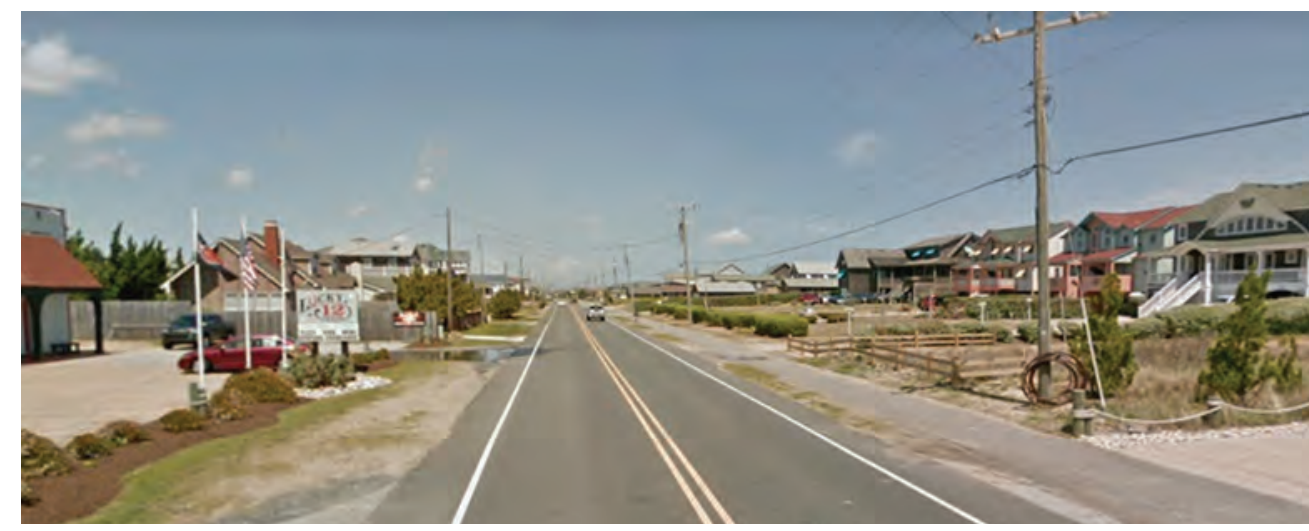

2. United States Route 158 (US 158 / South Croatan Highway) is a two-way, five-lane undivided arterial highway with a center turn lane. It has a posted speed limit of $45 \mathrm{mph}, 11$-foot travel lane widths, and similar to NC 12 has solid white edge lines and 3.5-foot wide shoulders (see Figure 2).

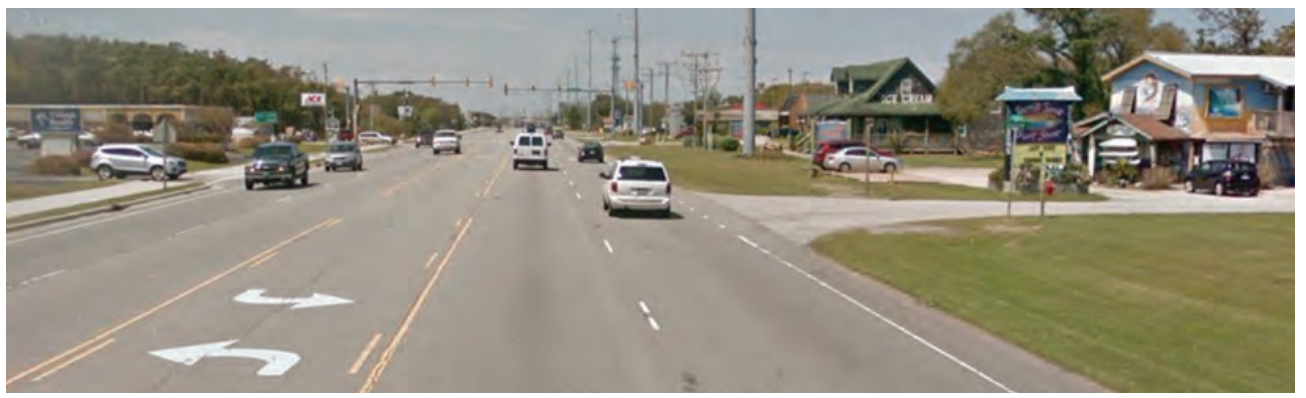

All four of the signs along NC 12 were viewed from the northbound lane with the signs on the driver's left, and therefore across one lane of traffic. Along US 158 two signs were viewed from the southbound travel lane and two from the northbound. As with NC 12, signs were on the driver's left, however, the viewing distance was greater given the number of lanes.
Figure 1 / North Carolina Highway 12, looking northbound

Figure 2 / United States Route 158, looking northbound 


\section{Data Collection}

After permission was obtained from store managers, letter heights and offsets from the roadway edge lines were measured. The experimenters then determined the Maximum Available Legibility Distances (MALD) and the distances at which the eight signs could be read from a moving vehicle (hereafter called Sign Legibility). The results are tabulated in Appendix B.

\section{Maximum Available Legibility Distance (MALD)}

As described by Garvey (2006), the MALD is the distance between the driver and the parallel mounted sign where the observation angle first allows the sign to become readable. This angle is critical in Garvey's calculations; combined with sign lateral offset it determines letter height. Per Garvey, minimum letter height for parallel signs is based first and foremost on achieving an angle at which the signs are capable of being read. Based on an exhaustive literature review, that was set conservatively at 30-degrees, as smaller angles result in too much foreshortening. The distance on the road upstream of the parallel sign, where this 30-degree angle is met, depends on lane number and width and the sign's offset from the road edge. Theoretically, a driver could not read the sign beyond that distance, no matter how large the letters or the sign.

The letter height calculation for parallel mounted signs is determined by a Legibility Index (LI) of 1 inch per 10 feet. For example, if the MALD is 300 feet, letters would need to be 30 inches tall, at a minimum, in order to be legible at that distance. This ratio was identified as such because the shorter distances and larger viewing angle of parallel signs must be counteracted. This makes the sign much easier and faster to read. In comparison, the LI ratio for perpendicular signs is 1 inch of letter height per 30 feet of the MALD, three times the distance. If the offset angle is smaller than 30-degrees the sign can be read further upstream, meaning a longer MALD, therefore necessitating a greater minimum letter height. A larger offset, which means that the observer must be closer to the sign to read it, would allow for a smaller minimum letter height.

To precisely determine the MALD for each of the test signs, and to field test the 30-degree observation angle, the two experimenters walked along the edge of the two roadways during daylight hours and in fair weather and dry conditions. The experimenters consisted of one female age 46 and one male age 58, both with vision corrected to 20/20 with glasses, neither with any visual impairment other than the need for corrective lenses. When the sample signs, given their angle, became legible, the experimenters marked the location with an iPhone 6S' GPS / mapping function. The experimenters continued to walk until they became parallel with the sign, where they again marked the location. The distance between these locations was calculated via an application called Distance Tool. This gave the experimenters the measurements necessary to determine the MALD and observation angle. This same procedure was repeated for each of the eight target signs.

\section{Legibility Distance}

The two experimenters, one driver and one passenger, drove a 1997 BMW 328i along the two roadways at the posted speed limit in daylight and under fair weather and dry conditions. The passenger was tasked with reading the target signs as soon as they were able to do so with certainty. As with determining the MALD, that location was marked using an iPhone 6S, and when the vehicle was aligned with the sign, the passenger again marked the location. This distance was also calculated with the Distance Tool Application and again, the observation angle was determined.

\section{Data Analysis and Results}

The findings of these empirical tasks were compared to the predicted outcomes in Garvey (2006) to determine the efficacy of those results and establish real-world appropriate minimum letter heights for parallel mounted signs (see Appendix B). Results show that the average observation angle found by driving was 27.75-degrees, very close to the 30-degrees calculated by Garvey (2006). However, the average observation angle found while walking was only 16.14 degrees.

According to calculations in Garvey (2006), the minimum letter height, in inches, for a parallel mounted sign is $10 \%$ of the MALD; this is given because of the LI ratio of 1:10. Appendix B (column E) shows 
the theoretical minimum letter height calculation per Garvey (2006); columns $\mathrm{L}$ and $\mathrm{V}$ highlight the values for the 8 signs in this study, given walking and driving measurements.

\section{Sign Size}

The letter heights and the number of letters on the eight signs were applied to an equation to determine the appropriate associated sign area in square feet. Table 1 (see below) shows an example of this, with a sign that has 30, 18-inch letters. In this calculation, letter height is assumed to be equal to letter width, which is conservative and takes into consideration inter-character spacing. For most fonts, the width to height ratio is less than one, meaning that letters are taller than they are wide. The Garvey (2006) theoretical letter heights, and the walking and driving tasks from the current study are shown in Appendix B (columns F, M, and $\mathrm{W}$ respectively).

Table 1 / A summary of evaluation tasks used to assess recall in Session 2 of the experiment.

\begin{tabular}{|l|r|}
\hline Sign Size Calculation: & \\
\hline Height of characters (in inches) & 18.00 \\
\hline Area for each character $\left(\right.$ in $\mathrm{ft}^{2}$ ), assuming letter width = height & 2.25 \\
\hline Number of characters $=30($ assuming 6 words with 5 characters each) & 30.00 \\
\hline Total area of all characters (in $\mathrm{ft}^{2}$ ) & 67.50 \\
\hline Area of negative space $\left(\right.$ in $\left.\mathrm{ft}^{2}\right)$, assuming industry standard of $60 \%$ of sign & 101.25 \\
\hline & \\
\hline Total sign size $\left(\right.$ in $\left.\mathrm{ft}^{2}\right)$ : text + neg. space & 168.75 \\
\hline
\end{tabular}

\section{CONCLUSION}

The 30-degree observation angle used in the parallel sign minimum letter height calculations found in Garvey (2006) is consistent with the mean of 28-degrees found in the driving legibility task conducted in this research. However, the observation angle of 16-degrees found when walking is roughly half. If this angle were substituted, the minimum recommended letter heights are roughly doubled and sign sizes quadrupled.

To determine whether or not the data warrant using these larger letter heights, a closer evaluation of the results was conducted. Two of the eight signs tested (Life is Good and Midgett's Seafood) used letter heights that exceeded Garvey's (2006) recommendations. Of those, Midgett's Seafood had appreciably increased legibility distances, increased MALD, and reduced observation angles. The Life is Good sign may have had similar results, but the letters were faded by the sun, thereby reducing both contrast and legibility.

This study, a follow up to Garvey (2006), found that smaller observation angles, and therefore larger letter heights and sign sizes, can improve the legibility distance of parallel mounted signs and bring their performance closer to that of perpendicular signs. Due to the nature of the experimental design, using real 
signs in the built environment vs. geometric calculations used in the earlier research, there were some uncontrollable variables, such as letter height, font, contrast, and offset. Future research is recommended to further validate these results using a larger subject sample size and greater experimental control over sign characteristics. This could be achieved by incorporating a closed track and specially designed signs into the experiment.

\section{ACKNOWLEDGMENTS}

The research conducted for this paper was funded by a generous grant from The United States Sign Council Foundation.

\section{REFERENCES}

Garvey, P.M. (2006). Determination of parallel sign legibility and letter heights. United States Sign Council (USSC) Research Project, Final Report. https:/usscfoundation.org/wp-content/uploads/2018/03/USSC-Parallel-Sign-Legibility-2018.pdf

United States Sign Council Foundation (USSCF). (2006). Computation equations: sign area; viewer reaction; projection control; letter height. United States Sign Council Foundation Report. https://usscfoundation.org/wp-content/uploads/2018/03/USSCFComputation-Equations-2018.pdf

Zineddin, A.Z., Garvey, P.M., and Pietrucha, M.T. (2005). Impact of sign orientation on on-premise commercial signs. ASCE: Journal of Transportation Engineering, 131(1), 11-17. 


\section{APPENDICES}
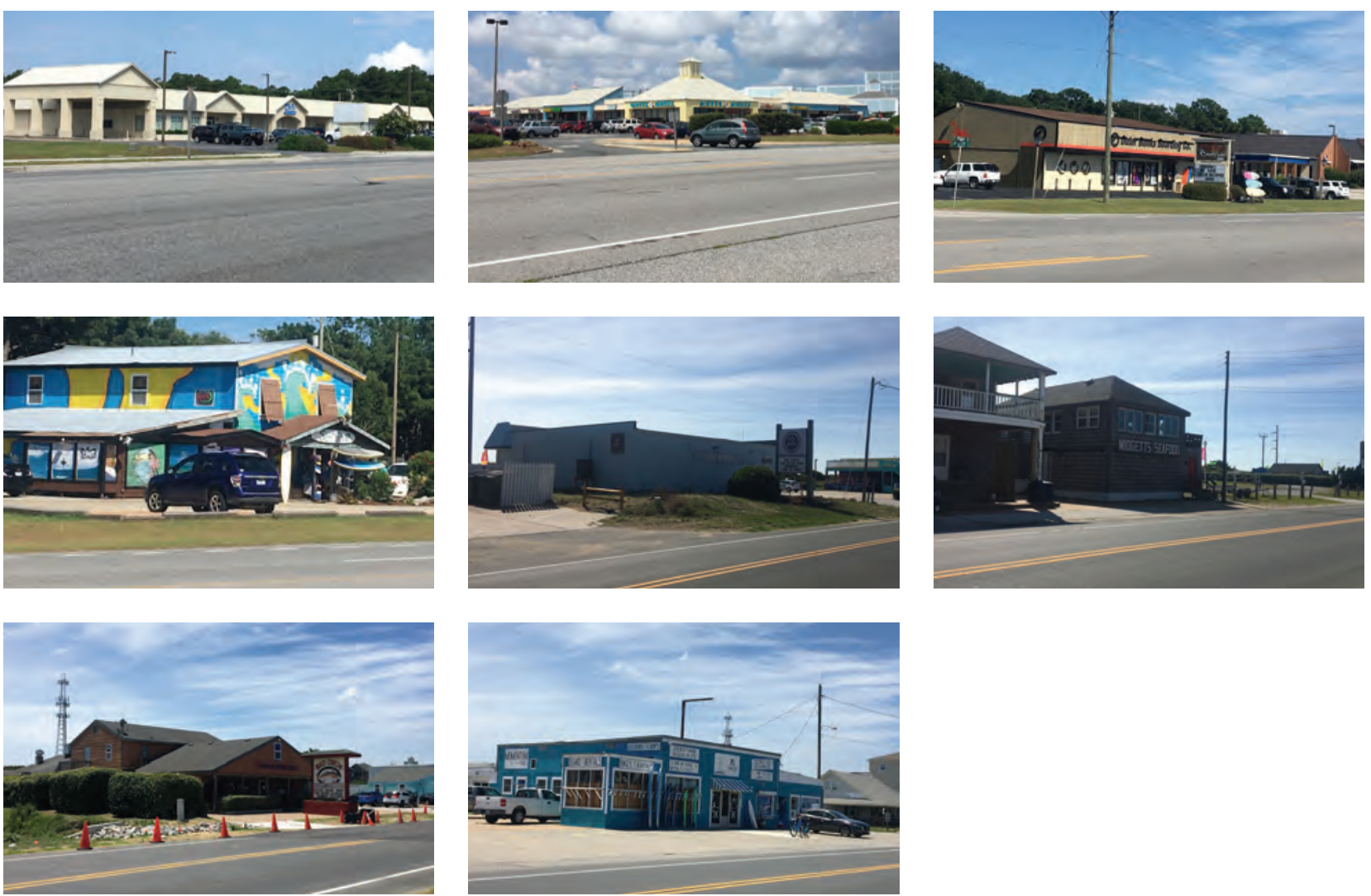

Appendix A / Signs in varied letter heights and lateral offset from the roadway.

\begin{tabular}{|c|c|c|c|c|c|c|c|c|c|c|c|c|c|c|c|c|c|c|c|c|c|c|}
\hline \multicolumn{23}{|c|}{ Appendix B: Data } \\
\hline & $\begin{array}{c}\text { Number of } \\
\text { Letters }\end{array}$ & Sign Offset & \multicolumn{2}{|c|}{ Letter Height } & Sign Size & \multicolumn{5}{|c|}{ Maximum Available Legibility Distance (MALD) } & Letter Height & Sign Size & \multicolumn{10}{|c|}{ Sign Legibility (Measured while driving at posted speed limit) } \\
\hline \multirow{3}{*}{\begin{tabular}{c|} 
N.C. 12 \\
Red Drum Seafood
\end{tabular}} & \multirow{3}{*}{\begin{tabular}{|c|} 
Measured \\
17 \\
17
\end{tabular}} & \multirow{3}{*}{$\begin{array}{c}\text { Measured } \\
\text { Feet } \\
39.34 \\
\end{array}$} & \multirow{3}{*}{$\begin{array}{c}\text { Measured } \\
\text { Inches } \\
12\end{array}$} & \multirow{3}{*}{\begin{tabular}{|c}
$\begin{array}{c}\text { Garvey, } \\
\text { (2006) } \\
\text { Calculated } \\
\text { Minimum }\end{array}$ \\
Inches \\
11.87 \\
\end{tabular}} & \multirow{3}{*}{$\begin{array}{c}\begin{array}{c}\text { Garvey, } \\
\text { (2000) } \\
\text { Calculated } \\
\text { Minimum }\end{array} \\
\mathrm{ft}^{2} \\
41.57 \\
\end{array}$} & \multicolumn{2}{|c|}{$\begin{array}{l}\text { Garvey (2006) } \\
\text { Calculated based on } \\
\text { measured offset and } \\
\text { assumed } 30 \text { degree } \\
\text { observation angle. }\end{array}$} & \multicolumn{5}{|c|}{ Measured in walking study } & \multirow{2}{*}{\multicolumn{2}{|c|}{$\begin{array}{c}\text { Observer } 1 \\
\text { Feet }\end{array}$}} & \multirow{2}{*}{\multicolumn{2}{|c|}{\begin{tabular}{|c|} 
Observer 2 \\
Feet
\end{tabular}}} & \multicolumn{6}{|c|}{ Mean of 2 observers, 2 observations each } \\
\hline & & & & & & Feet & Seconds & Feet & Seconds & $\begin{array}{l}\text { Observation } \\
\text { Angle (deg) }\end{array}$ & $\begin{array}{l}\text { Minimum } \\
\text { (inches) }\end{array}$ & Minimum $\left(\mathrm{ft}^{2}\right)$ & & & & & \multirow{2}{*}{$\begin{array}{c}\text { Feet } \\
106.50\end{array}$} & \multirow{2}{*}{\begin{tabular}{|c|} 
Seconds \\
2.07 \\
\end{tabular}} & \multirow{2}{*}{$\begin{array}{r}\text { MALD } \\
121.75 \\
\end{array}$} & \multirow{2}{*}{$\begin{array}{c}\begin{array}{c}\text { Observation } \\
\text { Angle (deg) }\end{array} \\
28.98 \\
\end{array}$} & \multirow{2}{*}{\begin{tabular}{|c|c|}
$\begin{array}{c}\text { Minimum } \\
\text { Letter Height } \\
\text { (inches) }\end{array}$ \\
12.18 \\
\end{tabular}} & \multirow{2}{*}{\begin{tabular}{|c}
$\begin{array}{c}\text { Minimum Sig } \\
\text { Size }\left(\mathrm{ft}^{2}\right)\end{array}$ \\
43.75
\end{tabular}} \\
\hline & & & & & & 118.68 & 2.31 & 234 & 4.40 & 14.63 & 23.40 & 161.61 & 67 & 71 & 141 & 147 & & & & & & \\
\hline $\begin{array}{l}\text { Farm Dog Surf } \\
\text { School }\end{array}$ & 21 & 39.42 & 9 & 11.88 & 51.49 & 118.84 & 2.32 & 245 & 4.66 & 13.86 & 24.50 & 218.84 & 82 & 82 & 170 & 139 & 118.25 & 2.30 & 132.15 & 26.52 & 13.22 & 63.67 \\
\hline Life is Good & 10 & 44.50 & 14 & 12.90 & 28.89 & 129.00 & 2.51 & 242 & 4.54 & 15.36 & 24.20 & 101.67 & 115 & 136 & 142 & 116 & 127.25 & 2.48 & 142.66 & 26.88 & 14.27 & 35.33 \\
\hline Midgetts Seafood & 15 & 31.50 & 23 & 10.30 & 27.63 & 103.00 & 2.01 & 266 & 5.08 & 11.16 & 26.60 & 184.26 & 155 & 147 & 160 & 171 & 158.25 & 3.08 & 166.42 & 18.03 & 16.64 & 72.12 \\
\hline \multicolumn{23}{|l|}{ U.S 158} \\
\hline $\begin{array}{l}\text { Secret Spot Surf } \\
\text { Shop }\end{array}$ & 8 & 74.00 & 20 & 24.80 & 85.42 & 248.00 & 4.83 & 288 & 5.07 & 25.50 & 28.80 & 115.20 & 153 & 142 & 125 & 169 & 147.25 & 2.87 & 192.51 & 40.10 & 19.25 & 51.47 \\
\hline $\begin{array}{c}\text { Outer Banks } \\
\text { Boarding Company }\end{array}$ & 20 & 93.50 & 28 & 28.70 & 286.00 & 287.00 & 5.59 & 505 & 9.43 & 16.51 & 50.50 & 885.50 & 339 & 374 & 341 & 352 & 351.50 & 6.85 & 379.66 & 22.21 & 37.97 & 500.49 \\
\hline Grits 'n Grill & 10 & 108.00 & 24 & 31.60 & 173.36 & 316.00 & 6.16 & 549 & 10.25 & 11.60 & 54.90 & 523.27 & 262 & 220 & \begin{tabular}{|l|}
319 \\
\end{tabular} & 298 & 274.75 & 5.35 & 316.94 & 29.90 & 31.69 & 174.39 \\
\hline $\begin{array}{l}\text { Department of Motor } \\
\text { Venicles }\end{array}$ & 3 & 148.50 & 30 & 39.70 & 82.09 & 397.00 & 7.73 & 528 & 9.53 & 20.50 & 52.80 & 145.20 & 325 & 312 & 376 & 397 & 352.50 & 6.87 & 404.55 & 29.39 & 40.46 & 85.24 \\
\hline Mean & & & & & & & & & & 16.14 & & & & & & & & & & 27.75125 & & \\
\hline
\end{tabular}

Appendix B / Analysis determining the Maximum Available Legibility Distances (MALD) and the distances at which the eight signs could be read from a moving vehicle. 